\title{
OBSERVACIONES A "SOBRE EL CONCEPTO \\ DE HISTORIA” DE WALTER BENJAMIN
}

EDUARDO JOCHAMOWITZ

"Sobre el concepto de historia" es un escrito póstumo de Walter Benjamin. Fue redactado entre 1939 y 1940 en diversos cuadernos, papeles sueltos y bordes de periódicos. Publicado y titulado en 1942 por Theodor Adorno en EE.UU., reúne diecinueve tesis sobre la escritura y producción de la historia. El escrito está lejos de ser un cuerpo ordenado de postulados y premisas en torno a la historia y su ejercicio. La interpretación que quiero sostener en este trabajo es que las tesis constituyen una toma de posición consciente e intencionada. Frente al marxismo convertido en totalitarismo soviético y una idea de progreso acrítica, Benjamin articulará una posición teórica y política. Las tesis aquí expuestas son fruto de un tiempo particular. Benjamin compuso estas tesis en una época de persecución y barbarie. La década de los años 30 es el escenario de la ascensión del fascismo y la transformación del socialismo en totalitarismo. Benjamin fue testigo en carne y hueso de la persecución a los judíos, de la sumisión de las supuestas democracias europeas al régimen nazi (Tratado de Munich de 1938) y el fracaso de la Revolución rusa (Pacto germano-soviético de 1939). La reacción ante estos acontecimientos será un intento de mostrar como el pasado puede y debe cuestionar y sabotear el orden del presente.

Para comprender como Benjamin sostiene estas tomas de posición quiero, primero, mostrar el concepto de historia que formula Benjamin y cuál es su relación con el marxismo. En segundo lugar, quiero desarrollar la visión particular de Benjamin sobre la idea de progreso y sus consecuencias para la vida. 
Finalmente, quiero mostrar cómo la toma de conciencia de las condiciones de producción de la historia conduce a la acción política y revolucionaria.

\section{§ 1. Historia}

Las tesis comienzan con una comparación entre el turco mecánico y el materialismo histórico. El turco mecánico pretende ser un autómata con la habilidad de jugar al ajedrez y siempre salir victorioso. Es una máquina que crea la ilusión de ser autosuficiente, de dominar todas las posibles combinaciones de una partida. Sin embargo, es una construcción ilusoria: dentro del mecanismo se oculta un enano que manipula la máquina. El materialismo histórico, la doctrina filosófica que explica el desarrollo de la historia a partir de las condiciones materiales que organizan la vida de los hombres, comparte un rasgo sustancial con este autómata ilusorio: ambos ocultan algo en su interior que garantiza la victoria, la teología. Así, la propuesta de Benjamin en esta primera tesis es cuestionar a la historiografía marxista y cristiana. El materialismo histórico que Benjamin critica aquí es aquel que concibe a la historia como un proceso cognoscible y demostrable de forma necesaria. La teología cristiana comprende a la historia como un gran proceso divino o del espíritu, un proceso incesante donde los individuos son tan sólo el insumo de un plan divino'. El teólogo sería aquel que reconoce esta gran verdad y así reconoce que todos los acontecimientos de la historia son parte de un fin último. De forma semejante, el materialismo histórico que defendía el marxismo vulgar opera bajo los mismos principios: pretende explicar el presente a partir de las condiciones materiales y las formas de producción del pasado. Ocurre así que la historia tiene un decurso necesario determinado por las contradicciones materiales. La comparación con el autómata se hace más clara: "En la filosofía, uno puede imaginar un equivalente de ese mecanismo; está hecho para que venza siempre el muñeco que conocemos como 'materialismo histórico'. Puede competir sin más con cualquiera siempre que ponga a su servicio a la teología, la misma que hoy, como se sabe, además de ser pequeña y fea, no debe dejarse ver por nadie"2.

I Cf. Löwith, Karl, Historia del mundo y salvación: los presupuestos teológicos de la filosofía de la historia, Buenos Aires: Katz, 2007, pp. 13-18 y especialmente el capítulo tercero, pp. 7I-77.

2 Benjamin, Walter, Tesis sobre la historia y otros fragmentos, México D.F.: Ítaca, 2005, Tesis I, p. 35. En lo que sigue, citaré la tesis y el número de página de esta edición. 
El marxismo que adopta una visión semejante de la historia se convierte en un pensamiento acrítico, capaz de formular verdades absolutas y así vencer, de forma ilusoria, a cualquier postura rival.

En la segunda tesis, Benjamin introduce una primera consideración sobre la experiencia del tiempo: “'A las peculiaridades más notorias del espíritu humano, dice Lotze, pertenece... junto a tanto egoísmo en lo particular, una falta de envidia general de todo presente respecto de su futuro.' Esta reflexión apunta hacia el hecho de que la imagen de felicidad que cultivamos se encuentra teñida por completo por el tiempo al que el curso de nuestra propia existencia nos ha confinado" ${ }^{3}$. Esta primera imagen del tiempo que esboza Benjamin sugiere una idea importante: la relación del presente con el pasado es más significativa que la del presente con el futuro. El futuro siempre está abierto como posibilidad, aún no lo hemos perdido o desperdiciado; en cambio, el pasado sí tiene la capacidad de afectar al presente: el curso de nuestra propia existencia nos ata continuamente con él. Para Benjamin, el pasado constituye un poder que no puede ser agotado ni clausurado, pues no deja de interpelarnos lo que podría haber sido. El pasado exige del presente una redención: "El pasado lleva oculto un índice oculto que no deja de remitirlo a la redención"4. "Redención" podría referirse aquí a la liberación de una carga o pena de un individuo por parte de otro. Si el pasado espera redención, es porque los individuos del presente tienen una obligación con el pasado, un compromiso que deben de redimir: "un secreto compromiso de encuentro está entonces vigente entre las generaciones del pasado y la nuestra. Es decir, éramos esperados sobre la tierra" 5 .

Si esto es así, Benjamin, con esta tesis, inicia la destrucción del tiempo como un espacio homogéneo que sólo mira hacia delante. El presente es conectado con el pasado a través de esta necesidad de redención. El mesías es para la tradición judía y cristiana el encargado de realizar la redención, mas para Benjamin esta tarea puede y debe ser llevada a cabo por todos: "También a nosotros, entonces, como a toda otra generación, nos ha sido conferida una débil fuerza mesiánica a la que el pasado tiene derecho de dirigir sus reclamos.

\footnotetext{
Tesis II, p. 36.

Ibid.

5 Ibid., p. 37.
} 
Reclamos que no se satisfacen fácilmente, como bien lo sabe el materialista histórico"6.

La tercera tesis introduce la tarea del historiador: "El cronista que hace la relación de los acontecimientos sin distinguir entre ellos los grandes y los pequeños responde con ello a la verdad de que nada de lo que tuvo lugar alguna vez debe darse por perdido para la historia"7. Benjamin marca así un compromiso en el acto mismo de registrar la historia; el historiador no debe responder para plegarse a una verdad parcial, pues todos los acontecimientos pasados son significativos para el presente. Con esta postura se afirma la idea de redención de la tesis anterior, pues todo hecho pasado exige una respuesta del presente. Sin embargo, Benjamin hace seguidamente una aclaración: "Aunque, por supuesto, sólo a la humanidad redimida le concierne enteramente su pasado. Lo que quiere decir: sólo a la humanidad redimida se le ha vuelto citable su pasado en cada uno de sus momentos" ${ }^{\text {. }}$

Las tesis IV y $\mathrm{V}$ están dedicadas a aclarar cómo los elementos del pasado interpelan al presente: "La lucha de clases que tiene siempre ante los ojos el materialista histórico educado en Marx es la lucha por las cosas toscas y materiales, sin las cuales no hay cosas finas y espirituales. Estas últimas, sin embargo, están presentes en la lucha de clases de una manera diferente de la que tienen en la representación que hay en ellas como botín que cae en manos del vencedor. (...) Van a poner en cuestión, siempre de nuevo, todos los triunfos que alguna vez favorecieron a los dominadores" 9 . Benjamin, pienso, se refiere aquí a que la escritura de la historia no puede ser definitiva. A pesar de que la clase dominante produzca los discursos oficiales sobre el pasado para justificar al presente, nunca puede detener el retorno de aquello que quiso silenciar, no puede callar la voz de los oprimidos. El historiador sincero, que no está al servicio de legitimar al presente, tiene la difícil tarea de atrapar la imagen del pasado que regresa y sólo es capaz de hacerlo si tiene un compromiso político con el presente: "La imagen verdadera del pasado pasa de largo velozmente. El pasado sólo es atrapable como la imagen que refulge,

\footnotetext{
Ibid.

Tesis III, p. 37.

Ibid.

9 Tesis IV, p. 38.
} 
para nunca más volver, en el instante en que se vuelve reconocible. (...) la imagen verdadera del pasado es una imagen que amenaza con desaparecer con todo el presente que no se reconozca aludido en ella"10. La idea de redención vuelve aquí a aparecer, el historiador comprometido será entonces aquel que se sienta aludido por la imagen del pasado que irrumpe y refulge, que rompe con el continuo del tiempo y reclama ser redimida.

La tesis VI presenta un tono normativo dirigido al historiador que toma una posición política: "Articular históricamente el pasado no significa conocerlo 'tal como verdaderamente fue'. Significa apoderarse de un recuerdo tal como éste relumbra en un instante de peligro. De lo que se trata para el materialismo histórico es de atrapar una imagen del pasado tal como ésta se le enfoca de repente al sujeto histórico en el instante de peligro. El peligro amenaza tanto a la permanencia de la tradición como a los receptores de la misma. Para ambos es uno y el mismo: el peligro de entregarse como instrumentos de la clase dominante" "I. Así queda precisada la tarea del historiador: defender las formas de vida presentes en una tradición del peligro de convertirse en un instrumento. El historiador debe hacer valer la dignidad de cada vida humana frente a los intereses materiales y dominadores. Mientras una tradición tenga una voz que la defienda, no puede caer en un curso "necesario" de la historia. Sin embargo, Benjamin no es nada idealista en este punto, sabe que la historia del hombre ha sido una historia de dominación y silencios, que toda victoria y progreso se ha pagado muy caro a pesar de lo que digan los libros habitualmente: "Encender en el pasado la chispa de esperanza es un don que sólo se encuentra en aquel historiador que está compenetrado con esto: tampoco los muertos estarán a salvo del enemigo si éste vence. $Y$ este enemigo no ha cesado de vencer"'2.

\section{§ 2. Progreso}

El curso necesario de la historia se puede identificar con el discurso que justificó la idea de un Reich de mil años o un socialismo eterno. Ambas ideologías,

\footnotetext{
10 Tesis V, p. 39.

"Tesis VI, p. 40.

12 lbid.
} 
ancladas en un tiempo continuo, afirmaban su derecho sobre la historia en nombre del progreso. La posición de Benjamin sobre el progreso es crítica y negativa: es la mayor fuente de destrucción de lavida humana, es la patología social por excelencia del siglo $X X$. En la tesis IX, a partir de una interpretación de un cuadro de Paul Klee titulado Angelus novus, aparece la imagen del progreso de Benjamin: "Se ve en él un ángel, parece en el momento de alejarse de algo sobre lo cual clava la mirada. Tiene los ojos desorbitados, la boca abiertay las alas tendidas. El ángel de la historia debe tener este aspecto. Su rostro

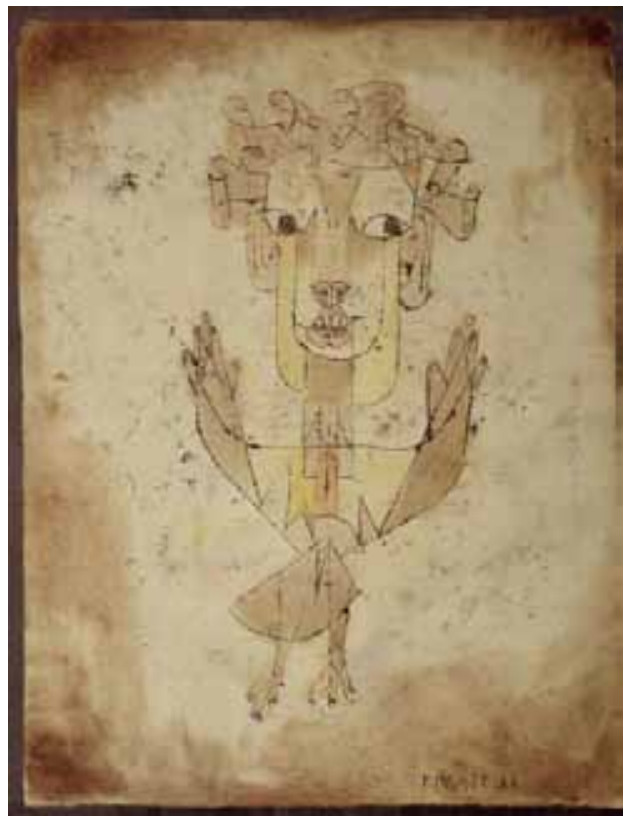

Paul Klee, Angelus novus (1920).

Tinta, tiza y aguada sobre papel, $31.8 \times 24.2 \mathrm{~cm}$.

The Israel Museum

$<$ http://www.english.imjnet.org.il/htmls/popup. aspx?c0 $=|3336 \& b s p=| 3263>$

lo que a nosotros aparece como una cadena de acontecimientos, él ve una catástrofe única, que arroja a sus pies ruina sobre ruina, amontonándolas sin cesar"13.

Benjamin exige de esta tesis una interpretación especial, donde se combinan elementos estéticos y judíos. Un ángel de la historia es sólo posible para Benjamin por su tradición judía, que proclama la creación incesante de ángeles enviados por Dios en auxilio de la humanidad. Este ángel, sin embargo, es impotente. Su mirada hacia el pasado es desesperada y reveladora. Donde la humanidad quería leer un progreso de bienestar y civilización, el ángel sólo ve una acumulación incesante de ruinas. El tiempo que la modernidad concebía como una "cadena de acontecimientos" es para el ángel una tragedia única 
donde cada acontecimiento es devorado y privado de su valor propio. La tesis continúa: "El ángel quisiera detenerse, despertar a los muertos y recomponer lo destruido. Pero un huracán sopla desde el paraíso y se arremolina en sus alas, y es tan fuerte que el ángel ya no puede plegarlas. Este huracán lo arrastra irresistiblemente hacia el futuro, al cual vuelve las espaldas, mientras el cúmulo de ruinas crece ante él hasta el cielo"'/4.

El progreso es destrucción para Benjamin y su curso incesante se revela en la historia política de la Europa del siglo XX. Para el socialismo europeo, el trabajo era la fuente de progreso por excelencia; mientras más empeñada estuviese una sociedad en el trabajo, más pronto vería los frutos de su esfuerzo. "No hay otra cosa que haya corrompido más a la clase trabajadora alemana que la idea de que ella nada con la corriente. El desarrollo técnico era para ella el declive de la corriente con la que creía estar nadando"15. Trabajo como sinónimo de progreso será una segunda patología social identificada por Benjamin. Los líderes socialistas cometieron el error de confiar en la redención de la humanidad por el trabajo, así Josef Dietzgen, amigo de Marx y miembro del $V$ Congreso de la Internacional Comunista, es citado por Benjamin como síntoma del marxismo vulgar: "Trabajo es el nombre del Mesías del tiempo nuevo. En el (...) mejoramiento (...) del trabajo (...) estriba la riqueza, que podrá hacer ahora lo que ningún redentor pudo lograr"16. Esta redención por vía del trabajo requería de un desarrollo enorme de las fuerzas productivas del hombre, de ahí el desarrollo incesante de la técnica y de máquinas a lo largo de todo el siglo, que lejos de ponerse al servicio del hombre se convirtieron en su mayor amenaza. La técnica es entendida por este marxismo como dominación de la naturaleza, siempre al servicio del hombre, que pretende solucionar los problemas sociales por medio de la abundancia de bienes materiales; lo contrario no cabe en su imaginación: "Sólo está dispuesta a percibir los progresos del dominio sobre la naturaleza, no los retrocesos de la sociedad. Muestra ya los rasgos tecnocráticos con los que nos toparemos más tarde en el fascismo"'7.

\footnotetext{
14 lbid.

15 Tesis XI, p. 46.

16 Tesis XI, p. 47.

17 lbid.
} 


\section{§ 3. Acción política}

El reconocimiento de las consecuencias del tiempo histórico homogéneo que conduce al fetiche del progreso exige, para Benjamin, una toma de posición política. Una nueva conciencia histórica reclama una revolución. Las tesis han mostrado hasta ahora la posibilidad de un tiempo nuevo, mesiánico y redentor, que no se hunde en una sucesión infinita sino que reclama el poder del instante - la imagen del pasado sobre el presente. A partir de la tesis XIV, Benjamin formula la posibilidad de un tiempo nuevo que conduzca a la transformación radical: "La historia es objeto de una construcción cuyo lugar no es el tiempo homogéneo y vacío sino el que está lleno de 'tiempo del ahora' (jetztzeit)”|8. El "tiempo del ahora" es el tiempo revolucionario. Es un tiempo que no pone sus esperanzas en algún futuro por llegar, sino que inaugura la posibilidad del cambio en cualquier momento. Cada instante tiene el poder de romper el orden social del presente, cada instante carga la posibilidad de redimir el pasado, de que los muertos "no hayan muerto en vano".

Para Benjamin, la conciencia de la clase revolucionaria es la conciencia de su capacidad de "hacer saltar el continuum de la historia"'9. Abandona así la concepción clásica del marxismo en la que el proletariado redime al género humano desposeído y enajenado. La revolución ya no se origina a partir de la conciencia del interés de clase, sino de la conciencia histórica. Un ejemplo de esta conciencia es la relación entre revoluciones y calendarios. Los calendarios expresan la forma en que una colectividad experimenta la temporalidad. De esta forma, cada vez que se quiso fundar una nueva sociedad, se cambiaron los calendarios y el tiempo fue reiniciado a cero. Roma contó el paso del tiempo a partir de su fundación, el cristianismo instauró una nueva era, la Revolución francesa creó el calendario republicano y los ejemplos siguen. En esta línea, Benjamin cita un acontecimiento de la Revolución de julio en 1830: "Cuando cayó la noche del primer día de combate ocurrió que en muchos lugares

18 Tesis XIV, p. 5I. El traductor de la edición castellana pone el término entre paréntesis, pero debe ir en mayúsculas: Jetztzeit. Cf. Benjamin, Walter, "Über den Begriff der Geschichte”, en: Gesammelte Schriften, edición de Rolf Tiedemann y Hermann Schweppenhäuser, Frankfurt a.M.: Suhrkamp, 7 tomos, 14 volúmenes, I, 2, p. 70I. Nota del editor. 
de París, independientemente y al mismo tiempo, hubo disparos contra los relojes de las torres" 20 .

Finalmente, el tiempo como "tiempo del ahora" es también un tiempo singular. No recibe su significado de una construcción metahistórica que "deja que otros se agoten con la puta del 'hubo una vez', en el burdel del historicismo" ${ }^{21}$. Cada instante reclama su propio valor fuera de una sucesión continua y detiene el pensar. Así, todo lo que nos era familiar, los objetos, las costumbres y las relaciones habituales, pierde su significado, entra en crisis y requiere un nuevo sentido. El "tiempo ahora" contempla cada cosa en su singularidad, como una mónada: "Cuando el pensar se para de golpe en medio de una constelación saturada de tensiones, provoca en ella un shock que la hace cristalizar como mónada. En esta estructura reconoce el signo de una detención mesiánica del acaecer o, dicho de otra manera, de una oportunidad revolucionaria en la lucha por el pasado oprimido" 22 . La visión de cada acontecimiento en tanto mónada trae en sí un procedimiento dialéctico: lo que antes era un punto en una sucesión es negado al ser puesto como una singularidad; la conciencia que recoge ambos momentos, que reconoce la oposición entre ambas experiencias de la temporalidad, es capaz de conferirle una fuerza mesiánica a ese evento. La tarea política del materialista histórico será identificar una situación política dada, reconocerla en toda su especificidad, en su dominación, y enfrentarse a ella en cada acto posible, en cada instante posible, sin esperar que la historia siga su curso. El pasado, todo lo perdido y destruido para construir el presente, se lo reclama al revolucionario.

\footnotetext{
20 Ibid.

21 Tesis XVI, p. 53.

${ }^{22}$ Tesis XVII, p. 54.
} 